\title{
Um olhar para a formação de formadores na formação continuada na educação infantil
}

\section{A view over teacher's trainers capacitation in a context of continuing formation in children education}

Maria Virgínia Gastaldi é mestre em Educação: Psicologia da Educação pela Pontifícia Universidade de São Paulo (PUC-SP), formadora e coordenadora de projetos do Instituto Avisa Lá, assessora de redes públicas e escolas particulares de educação infantil.

Contato: mariavir.gastaldi@gmail.com

\section{Resumo}

Considerando-se que o formador é figura central na criação, na organização e no desenvolvimento de espaços de reflexão e construção coletiva de conhecimentos no trabalho de formação continuada, foram investigados os processos formativos relativos à sua inserção em um modelo colaborativo de formação continuada na rede pública. A investigação foi efetuada por meio de grupos de discussão com formadores experientes. Os resultados revelam um começo difícil e penoso, bem como um alto investimento pessoal (pelos próprios formadores) e institucional, apontando para a importância do reconhecimento da complexidade da tarefa do formador e da formulação de políticas de formação e retenção de formadores.

Palavras-chave: formação continuada; formação de formadores; educação infantil.

\section{Abstract}

Teacher's trainers are the main actors in creating, organizing, and developing a roadmap towards building a collaborative and reflexive body of knowledge on continuing 
formation. Taking it into consideration, processes based on the continuing formation reference frame that aimed at inserting these actors into this very framework were investigated, through discussion groups constituted by senior professionals. on the results reveal a difficult and painful beginning, as well as high personal (the professionals themselves) and institutional investments, pointing out the importance of recognizing the high complexity of the teacher's trainers' professional role, and, consequentially, of formulating public policies towards capacitating and maintaining these professionals in the public network. Keywords: continuing formation; teacher's trainers; children education.

0 reconhecimento da importância estratégica da formação continuada para a melhora da qualidade da educação, em todos os níveis de ensino e para o desenvolvimento profissional dos professores, implica construir espaços formativos para o coletivo dos profissionais no ambiente institucional em que trabalham. Nas redes públicas, um dos grandes desafios é implantar uma cultura de formação permanente com ações sistemáticas, apoiando a construção do papel profissional de formadores locais, legitimados como tal por sua condição de poder cooperar e fazer com que o trabalho avance. Não se trata de tarefa simples.

As experiências nesse sentido são recentes e nem todas correspondem a resultados nas aprendizagens dos alunos e no desenvolvimento profissional dos professores. Um exemplo bemsucedido é a formação continuada de profissionais de educação infantil em Curitiba (Paraná), ${ }^{1}$ local onde, nos últimos anos, houve investimento do município na estruturação das equipes técnicas, na formação de formadores e no desenvolvimento de ações sistemáticas de formação, tendo sido implantada ali uma cultura de formação permanente na qual técnicos são sujeitos e reeditores reflexivos das propostas.

Considerando-se que o formador é figura central na criação, na organização e no desenvolvimento de espaços de reflexão e construção coletiva de conhecimentos, os processos formativos relativos à inserção desses profissionais em um modelo de formação continuada colaborativo na rede pública foram tomados como objeto de investigação. Para tanto, organizaram-se três grupos de discussão com formadores experientes de educação infantil. Os participantes foram selecionados com base no tempo e na qualidade da experiência como formador.
1. Contexto da pesquisa Formação continuada na educação infantil: possibilidades e desafios na perspectiva do formador, apresentada em 2012 no curso de mestrado em Educação: Psicologia da Educação, na Pontifícia Universidade Católica de São Paulo. 


\section{A formação do formador}

A formação é uma tarefa inerente ao trabalho do formador. Entendida como um espaço de desenvolvimento e mudança no qual aprendem os professores e o próprio formador (VAILLANT; MARCELO, 2001). Ser formador na formação continuada em uma rede de educação infantil demanda conhecimentos da prática pedagógica e características pessoais como liderança, criatividade e inovação, ou seja, um conjunto de requisitos pessoais nem sempre possível em um único profissional. Nesse sentido, ocorre com a formação de formadores

\footnotetext{
[...] o mesmo que ocorre com o ensino: a crença de que o único que se requer para ensinar é o conhecimento do que se ensina - o conteúdo ou matéria a ser ensinado. Esta tem sido uma crença bastante difundida e que foi acompanhada de um déficit de consideração social a respeito da complexidade que a tarefa de ensinar representa. Pois bem, poderia parecer que qualquer um pode exercer a função de formador de formadores, desde que seja especialista em alguma disciplina. Nada mais distante da realidade. (VAILLANT, 2003, p. 28)
}

Para Vaillant (2003), a discussão sobre a formação dos formadores centra-se em como ensinar o docente a utilizar com seus alunos os conhecimentos teóricos adquiridos durante sua própria formação. 0 conhecimento pedagógico e disciplinar dos formadores envolve: a formação pedagógica para o planejamento e o desenvolvimento de ações destinadas a um adulto profissional e para um trabalho "em terceiro grau, formando adultos que formarão jovens ou adultos" (VAILLANT, 2003, p. 29); o conhecimento adequado dos conteúdos disciplinares que serão ensinados; o conhecimento didático do conteúdo a ser ensinado; e o conhecimento do contexto do trabalho.

\section{0 começo é difícil e penoso}

Muitas vezes, o formador é um pedagogo da rede convocado a assumir a formação na implantação de um programa de formação. Nessa circunstância, como se aprende a ser formador? Considerando-se que não há cursos superiores especializados em formar profissionais para desempenhar o papel de formadores na formação continuada e que ninguém nasce formador, conhecer e entender de que modo os profissionais aprendem a ser formadores pode trazer contribuições para pensar a formação dos formadores. 
0 início do trabalho com a formação em serviço é relatado como tendo sido muito difícil, mesmo para aqueles profissionais que participaram diretamente dos encontros de formação desde o princípio da formação continuada. Isso se deveu à sobreposição das novas tarefas e dos primeiros contatos com os conteúdos estabelecidos, para a formação. 0 formador deveria realizar ações que simultaneamente levassem em conta os conteúdos da formação relativos à educação infantil e à própria formação, ambos abrangentes, complexos e novos para ele. 0 desconhecimento das propostas apresentadas no Referencial Curricular para a Educação Infantil (BRASIL, 1998), de onde emanavam os conteúdos a serem trabalhados, era, ao que parece, o que mais pesava e preocupava os formadores.

0 pedagogo formador sai de seu lugar de técnico que domina seu fazer para assumir um lugar, ao mesmo tempo, de aprendiz de um fazer, de dinamizador de aprendizagens no grupo de professores e de responsável por mudanças na prática da sala de aula. A aceitação do chamado para a formação e a determinação de estudar e aprender foram decisivas. A busca solidária entre os formadores tornou possível o desejo individual de aceitar o chamado para um novo papel profissional como forma de fazer frente às novas demandas da escola. 0 nível de sofrimento e as dificuldades iniciais apontam para a importância da rede de apoio que construíram e para a necessidade de os programas de formação criarem espaços de apoio e troca para os iniciantes.

Supostamente, em uma perspectiva como a do modelo vivido, em que existia um reconhecimento prévio de que "um professor experiente não se transformará, num passe de mágica, num coordenador experiente", pois estas "são funções diferentes que exigem uma profissionalização e uma profissionalidade pedagógica" (DOMINGUES, 2009 p. 100), haveria uma preocupação e um suporte para o início da difícil tarefa. No entanto, os depoimentos mostram que eles não foram suficientes, dadas a quantidade e a diversidade de novos saberes e fazeres com que os formadores teriam de lidar no novo papel. Esse é um indicador do alto grau de complexidade da função a ser assumida, bem como da amplitude e da diversidade dos novos saberes e fazeres a serem postos em ação pelo formador e que precisam ser considerados nos programas de formação.

A experiência dos formadores indica que a fase de implantação de uma proposta de formação continuada deve ser objeto de maior atenção e cuidado. Vaillant e Marcelo (2001, p. 115) salientam que "estudos mostram que um programa planificado, ainda que no 
papel seja excelente, frequentemente não se concretiza devido aos problemas que aparecem durante o processo de implementação".

A grande dificuldade em lidar com os conteúdos propostos indica a importância de garantir um melhor dimensionamento dos conhecimentos prévios do formador e dos conteúdos da própria formação, além de um tempo maior para que os formadores se familiarizem com os conteúdos a serem trabalhados. Assim como se reconhece a importância de os programas de formação darem suporte adequado para os diferentes ciclos da vida profissional dos professores, também no caso dos formadores é importante reconhecer e fazer encaminhamentos de apoios diferenciados nos diversos momentos de seu percurso.

Entendendo que todo apoio é necessário para manter e melhorar os quadros de formadores e sabendo que muitos desistem diante da perspectiva de assumir uma função tão complexa, conhecer as razões dos que permanecem pode ajudar a compreender melhor esse difícil começo. Sendo assim, a pergunta que se impõe é a seguinte: o que captura os profissionais que não desistiram perante uma situação que gerou altos níveis de sofrimento e ansiedade? Quando o formador se arrisca e assume a formação, descobre outro universo de possibilidades, trocas, parcerias e aprendizagens constantes. 0 progressivo domínio dos conteúdos possibilita o encantamento com a função e o ato de formar. Tal encantamento substitui o medo quando o formador aprende a fazer, sendo este o meio para que ele comece a construir uma identidade profissional e se legitime junto à equipe escolar e aos demais níveis da organização escolar. Em um contexto de tantas novas tarefas e atribuições, em meio a informações ainda não conhecidas, pode-se aprender a gostar quando se aprende a fazer. E quando se aprende a fazer e a gostar da relação com os profissionais na formação, não se quer mais voltar ao que se era, porque isso gera um movimento de conquista e contágio no grupo.

À primeira vista, a situação é quase paradoxal: o pedagogo não pode assumir a formação porque ainda não está preparado; porém, se não assumir, não saberá quanto pode ganhar como profissional e pode acabar por desistir. É necessário assumir a prática da formação para que o desejo de mais troca e aprendizagem seja despertado e mantenha ativa a imensa energia que precisa ser mobilizada. Nesse sentido, o princípio de aprender a fazer fazendo e de aprender a partir de uma prática profissional reflexiva pode ser um caminho a ser melhorado, ajustado, e não desprezado ou invalidado. 
Contagiar um grupo de professores com uma proposta de reflexão e mudança da prática é um resultado importante a se buscar na formação continuada. A vivência do gosto pela aprendizagem, pela troca e pela colaboração é imprescindível para a construção da escola que aprende, além de configurar um exemplo fundamental a ser fornecido pelos profissionais/adultos e pelo clima institucional perante a relação em construção das crianças com a escola e com a aprendizagem.

\section{0 que forma o formador?}

0 que contribuiu para a formação do formador? 0 que é legitimado por ele como meio para aprender a ser formador? Quais foram os meios utilizados para fazer frente às dificuldades da nova condição?

- A vivência como aprendiz no modelo de formação e as boas referências: o que contribuiu para a formação dos formadores foi, principalmente, ter boas referências de formador e vivenciar o modelo de formação. Tais aspectos foram abordados por todos os grupos participantes, reiteradamente. A menção ao papel fundamental de uma boa referência de formador na aprendizagem da função aponta para a importância e a responsabilidade dos profissionais que implantam esses programas. Aprender com a vivência, podendo pensá-la durante o próprio processo, é um meio poderoso para formar o formador e encantá-lo com o trabalho em questão. Ter participado e vivido a experiência da formação em um programa de formação continuada é apontado como essencial e diferente de ouvir falar ou ler sobre o assunto, o que se deve não apenas ao valor da experiência, mas ao reconhecimento de que a forma e o conteúdo da formação são indissociáveis, sendo a forma algo especialmente mais difícil de ser aprendido por outro meio que não a vivência de um contexto formativo. Uma boa referência possibilita que os formadores, caminhando em direção à sua própria autonomia como formador, passem, eles mesmos, por vários momentos em seu percurso: do difícil começo à criação e à autoria na ação formativa.

- A importância de um parceiro-formador para o formador: a presença de um profissional supervisor do formador que acompanha e discute sua prática dinamiza a troca e produz crescimento profissional. Com tal ação em cadeia, é possível 
falar em homologia dos processos, ou seja: em todos os níveis, trabalha-se com os mesmos princípios de autonomia e respeito à construção do conhecimento pelo sujeito. Essa forma de trabalho não é apenas validada pelos profissionais, mas considerada parte importante de sua formação. Nesse sentido, o reconhecimento do supervisor como parceiro importante no processo formativo é também um produto da própria formação continuada, e não uma perspectiva natural que sempre esteve ali presente, como pode parecer à primeira vista. Essa não é a mesma perspectiva encontrada em outras pesquisas (DOMINGUES, 2009).

- As estratégias que ajudam na formação do formador: os encontros mensais para formadores são reconhecidos como um espaço de reflexão e troca exclusivo do formador, em que ele pode estar com seus pares e dimensionar seu trabalho e seu percurso em relação aos demais. 0 espaço de troca com outro igual é visto, assim, como algo que confirma ou desestabiliza o formador. A formação dos formadores é resultado de um conjunto de situações, as quais parecem ter em comum uma mobilização do desejo de aprender e não apenas de ensinar. 0 conjunto de estratégias formativas é validado como espaços e tempos formativos em que os formadores podem conhecer outras experiências.

- 0 tempo, o espaço e os materiais: o tempo e o espaço garantidos para a formação, bem como os materiais produzidos internamente, os recursos e a organização de pessoal compõem o conjunto de encaminhamentos que tornam a formação possível.

0 formador se constitui como tal na própria ação formativa. E pode perceber isso olhando retrospectivamente para seu próprio percurso, vendo e avaliando seus avanços em um processo de aprendizagem permanente. Não há menção à formação inicial ou a outros cursos com algum tipo de contribuição para a formação dos formadores, o que fortalece o espaço da formação como de aprendizagem do formador.

As formas de aprender do formador podem ser pensadas também como parte de uma mudança mais geral nas modalidades e estratégias formativas: a passagem de um modelo de treinamento para um modelo mais indagativo e reflexivo, em que é possível o "intercâmbio entre os pares, ouvir de outros as boas práticas, a elaboração de projetos [...], uma nova maneira de organizar a formação" (IMBERNóN, 2009, p. 107). 
A complexidade da ação do formador e toda a dificuldade inicial podem modificar sua relação com os iniciantes, sendo que a experiência dos formadores tem muito a dizer sobre tais inícios. Assim, para os que se iniciam na formação em um modelo já em funcionamento, os formadores fazem algumas sugestões, tais como a participação em cursos para ingressantes com um panorama sobre a função e a convivência com profissionais mais experientes, porque, mesmo não sendo possível ensinar tudo no começo, estar com outro profissional pode evitar perda de tempo. Além disso, também é recomendado procurar conhecer bem os conteúdos e as estratégias de trabalho.

Placco, Almeida e Souza (2011), em recente pesquisa sobre o coordenador pedagógico e a formação continuada de professores no Brasil, defendem uma formação inicial específica para o coordenador formador. No que concerne à formação continuada, o mesmo estudo enfatiza a falta de formação específica para o formador, discutindo sobre as instâncias em que ela ocorre e sobre a importância da constituição da coordenação pedagógica como função específica.

\section{Formação continuada e desenvolvimento profissional}

Constituir-se formador implica desenvolver um corpo de saberes e competências na prática e a partir da reflexão sobre ela, predominantemente em contexto de formação continuada. Implica também aceitar o difícil desafio de aprender com a experiência e de aprender a desaprender muito do que se sabia anteriormente, a fim de dar lugar à construção de novos possíveis, em um caminho ainda por trilhar. Uma prática reflexiva pode conferir poder aos formadores e professores e proporcionar oportunidades para o seu desenvolvimento profissional. 0 formador descobre seu gosto por trabalhar e questionar junto com os professores, encontrando sua identidade profissional.

A possibilidade de seguir aprendendo é tão valorizada que é razão para preferirem trabalhar nessa e não em outra rede que não investe em formação continuada. Parece tratar-se da chamada vertente artística a que se refere Canário (2000): uma vertente inquiridora e reflexiva do trabalho docente e aqui estendida também para o trabalho do formador; a mesma que amedronta no início, mas que depois captura definitivamente o formador.

A formação acarreta crescimento pessoal: muda o estilo de vida, muda o jeito de pensar e agir, produz transformações na 
vida e na família, produz felicidade, faz as pessoas pensarem mais e possibilita a conquista de um espaço de relações e de respeitabilidade técnica. Por meio dela, aprende-se a ouvir mais, a continuar aprendendo, a ler mais. Nas palavras das participantes da pesquisa, a formação continuada deu maior desenvoltura para a vida pessoal e profissional, bem como "maior traquejo para se virar em situações difíceis" (PD2). Além disso, fortaleceu a confirmação da escolha profissional: "ser contador seria mais simples, mas não é a minha escolha" (PD3); "estou pedagoga, mas sou professora mesmo, por opção agora. De todas as idades" (PD2). Ainda, o trabalho com a formação demonstrou oferecer a possibilidade de se tornar mais humano e desenvolver um sentimento de compaixão em relação ao outro como alguém na mesma condição.

\section{Finalizando}

Podemos resumir o grande desafio de aprender a ser formador como sendo o desafio de manejar os tempos de aprender, de aprender a aprender e de aprender a ensinar. 0 formador aprende e ensina ao mesmo tempo, embora esteja sempre aprendendo; vê-se inserido em circunstâncias nas quais muitas vezes ainda não domina o conteúdo em questão e precisa reagir a elas no tempo da demanda, e não em seu próprio tempo. Controlar o impulso transmissivo é um desafio numa situação em que se faz necessário manejar muitos conhecimentos novos e dar respostas que, por sua vez, gerem mudanças.

Os espaços formativos e as parcerias para o formador são os caminhos para lidar com os desafios decorrentes do descompasso dos tempos de ensinar e aprender, o que aponta para a necessidade de os programas e as políticas de formação considerarem esse aspecto com mais atenção, investindo na formulação de metas e indicadores de avaliação compatíveis com os tempos da formação e passíveis de serem utilizados no monitoramento dos programas de formação de formadores.

A formação funciona também porque profissionais aceitam o chamado para ela e tomam a decisão pessoal de ir em busca de aprofundamento e parcerias, aceitando - e muitos se encantando - investir em uma nova identidade profissional, em uma nova profissão. Se os formadores não tomam para si a tarefa de compreender, reelaborar e levar adiante novas proposições, a formação em rede não se realiza dentro dos espaços formativos. $\mathrm{E}$ deve haver muito investimento pessoal de um formador para que ele se constitua como tal: ele estuda muito, trabalha intensamente 
sobre o novo, empenha-se em conseguir adesões, mudanças burocráticas e administrativas, envolve amigos e familiares para conseguir tempo, recursos e ajuda de toda ordem. Por isso, é preciso reconhecer sua importância e investir no formador, investir nas pessoas, pois são elas que fazem e encarnam as mudanças e as políticas. É preciso, assim, olhar seu trabalho com respeito e carinho, criando políticas de valorização e apoio a esse profissional nas diferentes fases de sua carreira e de acordo com as variações dos contextos de trabalho.

Com base nos resultados desta pesquisa, ficam aqui algumas sugestões:

- Investir em espaços de formação do formador: iniciativas de formação do formador para além do espaço da formação continuada, como a intensificação da oferta de cursos pelas universidades e centros especializados, bem como os fóruns de debate e troca de experiências organizados por especialistas, podem contribuir para fortalecer o formador em sua profissão e para diversificar (ou unificar) suas referências.

- Apoiar o formador iniciante: é preciso também criar e organizar formas de apoio ao formador iniciante, lembrando que, em casos como o da presente pesquisa, ele é convocado a mediar processos de reflexão sobre a prática e de construção de novos saberes em um contexto de dupla dificuldade: a de lidar simultaneamente com os saberes do formador e com os saberes do professor que ele não foi, levando em conta as grandes mudanças da educação infantil nas últimas décadas. Desenvolver e prever formas de aprender com formadores mais experientes, organizar modelos com tutores ou parceiros de referência para o formador e promover avaliações parciais podem ser alguns dos caminhos para isso.

- Investir no formador experiente: proporcionar a troca de experiências fora do contexto de trabalho, o intercâmbio de experiências bem-sucedidas, o encontro com outros pares, o apoio aos novos e a abertura de espaços de comunicação dos conhecimentos de cada profissional é uma forma de continuar investindo nos formadores experientes.

- Investir em documentação e acervo: criar ou dinamizar acervos públicos de documentos, textos, relatos de experiências etc. para consulta e apoio aos formadores é fundamental. 
- Fortalecer a formação continuada: em relação à formação continuada, o relatório da Fundação Carlos Chagas (FCC, 2011) propõe um conjunto de proposições para as políticas públicas, entre elas: incentivar a continuidade dos programas bem-sucedidos; investir na socialização de experiências bem-sucedidas; ampliar o tempo dedicado às ações de formação continuada, de modo que elas não se restrinjam apenas às reuniões pedagógicas coletivas na escola; avaliar os resultados dos programas de formação continuada.

- Desenvolver pesquisas e parcerias com a universidade e com instituições que trabalham com formação: pesquisas gerais sobre formadores no Brasil; pesquisas de acompanhamento de formadores em programas específicos ao longo do tempo; pesquisas que ajudem a desenvolver indicadores de acompanhamento e avaliação, principalmente no que se refere ao parcelamento e à progressão dos resultados ao longo dos diferentes tempos da formação e para os diferentes sujeitos nela envolvidos; a desenvolvimento e o acompanhamento de dispositivos de formação; e o monitoramento de programas de formação são contribuições importantes que podem dinamizar a parceria entre a academia e a formação continuada.

\section{REFERÊNCIAS}

BRASIL. Ministério da Educação e do Desporto. Secretaria de Educação Fundamental. Referencial curricular nacional para a educação infantil. Brasília: MEC/SEF, 1998.

CANÁRIO, Rui. A prática profissional na formação de professores. In: COLÓQUIO FORMAÇÃO PROFISSIONAL DE PROFESSORES NO ENSINO SUPERIOR. Anais... Aveiro: INAFOP, 2000.

DOMINGUES, Isaneide. O coordenador pedagógico e o desafio da formação contínua do docente na escola. Tese (Doutorado) - Faculdade de Educação, Universidade de São Paulo, São Paulo, 2009.

FUNDAÇÃO CARLOS CHAGAS (FCC). Formação continuada de professores: uma análise das modalidades e das práticas em Estados e Municípios brasileiros. Relatório final. São Paulo, 2011. Disponível em: <http://www.fvc.org.br/pdf/relatorioformacao-continuada.pdf>. Acesso em: 10 abr. 2012. 
IMBERNÓN, Francisco. Formação permanente do professorado, novas tendências. São Paulo: Cortez, 2009.

PLACCO, Vera Maria N. de Souza; ALMEIDA, Laurinda Ramalho de; SOUZA, Vera Lucia Trevisan de. O coordenador pedagógico e a formação de professores: intenções, tensões e contradições. Estudos e Pesquisas Educacionais, São Paulo, n. 2, p. 227-287, 2011.

VAILLANT, Denise. Formação de formadores: estado da prática. Santiago: PREAL, out. 2003. (Série PREAL Documentos, n. 25). Disponível em: <http://www.oei. es/docentes/articulos/formacion_formadores_estado_ practica_vaillant_portugues.pdf>. Acesso em: 10 abr. 2012.

VAILLANT, Denise; MARCELO, Carlos. Las tareas del formador. Málaga: Ediciones Aljibe, 2001.

Recebido em: 18/02/2013

Revisado em: 28/02/2013

Aprovado em: 12/03/2013 